\title{
A comparative study of social inequalities in education as an effect of Covid-19 pandemic: A case of schools in Saudi Arabia and Kenya.
}

\author{
James K Siambi \\ Graduate School, \\ Department of Organizational Leadership Pan Africa Christian University
}

\begin{abstract}
The Coronavirus epidemic is a major source of concern for global education systems and their ability to provide equity in education. Hundreds of countries closed schools during the Covid-19 in its first year to contain the mass spread of the virus. Over one billion students were denied an education as a result of Covid-19 school closures. This study compares the social inequalities experienced in schools in Kenya and Saudi Arabia following the outbreak of Covid-19. An extensive questionnaire on data collection methods was completed by educators, learners, and parents from public schools in these two countries. The statistics were calculated using the SPSS program while qualitative data was analyzed thematically. Covid-19 had a significant impact on the time used for learning, the content learned, and the quality of learning that was experienced in the sampled countries. The findings show that during the Coronary Syndrome outbreak, many learners and educators relied on technology to access continuing education. Unfortunately, inadequate infrastructures such as lack of network availability, structure, and proper policies hampered virtual education and expanded the social inequality between learners of the two sampled countries. The findings of this study highlight the devastating impact Covid-19 had on the education sector: schools, educators, learners, and parents. In brief, the success of continuity in education depended on the government policymaking and implementation that geared towards equity in the provision of education.
\end{abstract}

\section{Key words: Covid-19 pandemic, social inequalities, Saudi Arabia, Kenya}

\section{Introduction}

The expansion of education has not improved educational opportunity equity, nor has it diminished the general prevalence of generations at particular levels of education. There is indeed a considerable amount of socioeconomic inequity for several reasons but most recently is the impact of the Covid-19 pandemic on education. The net effects of social disparities in education are highly complex, and class reproduction, also known as social reproduction, is one of them. To solve these issues, educators from different disciplines search for the root causes from their perspectives. The functional theory, the progressive theory, the theory of educational wealth, and the theories of cultural deprivation are the four theories commonly being used to address the problem of social disparity in education. The educational system reflects any alternative solution from its point of view, showing both how society is viewed and the possibilities for improvement. This status quo is however overturned by the Covid-19 crisis on education and equity in education.

The latest Coronavirus outbreak has extended educational disparities to global proportions. Even though the Coronavirus pandemic is just a year old, it has already caused great damage. An outbreak of Covid-19 has contributed to both education inequality as well as to the health crisis in education. The coronavirus pandemic knew no bounds, and its effects were widespread and rapid. Within months of its emergence, the disease had drastically altered the way people lived theirs lived. Billions of people were compelled to remain indoors, others to work from home, and students to learn from home. It has curtailed people's ability to travel, share, and interact freely. Covid-19 has resulted in total lockdowns in several countries worldwide, as 
well as the deaths of thousands of people including children and the elderly. Even more concerning was the fact that reports from all continents and all countries revealed a steady increase in the number of new cases and deaths caused by Covid-19. There is also a rise in the number of survivors across the globe. The global Covid-19 case count had reached 123,849,701 cases as of March 21, 2021, with over 2,727,399 deaths. Despite the countries' strong commitment to fighting the virus, Saudi Arabia reported a total of 6,609 COVID-19 deaths while Kenya recorded a total of 2,011 deaths as of March 21, 2021. Both Saudi Arabia and Kenya had a total of 385,020 reported Covid-19 positive cases and 120,910 Covid-19 positive cases respectively (Worldometer, 2021). The number of Coronavirus deaths was on the rise, and no easy solutions were in sight despite the start of a free voluntary vaccination program in both countries.

To fully assess current-day measurement and accountability in education, the opportunity to learn must be made available to every learner hence the definition of equity. As the study's focus is on higher-order cognitive processes, opportunities for learning in education can be difficult to measure but this study focuses on the basic triage of measurement: Content, Time, and Quality (Elliott, 2015). The importance of the opportunity to learn and accomplishment as key constructs is stressed in today's large-scale evaluation and accountability frameworks. According to this definition, an opportunity to learn refers to how much time educators devote to particular curriculum goals that concentrate on higher cognitive processes by pursuing evidence-based practices and strategies (Floden, 2002). Education policymakers and educators occasionally address measurable targets as well as achievement and growth, but they are difficult to pinpoint due to their complex and unpredictable existence.

\section{Research Objectives}

1. Compare the time spent for learning in schools in Saudi Arabia and Kenya during the first year of the Covid-19 pandemic.

2. Compare the quality of learning in schools in Saudi Arabia and Kenya during the first year of the Covid-19 pandemic.

3. Compare the content learned in schools in Saudi Arabia and Kenya during the first year of the Covid-19 pandemic.

\section{Literature review}

\section{The impact of Covid-19 pandemic on education in Saudi Arabia}

In Saudi Arabia, teachers were required to work in different ways and adapt to an environment with strict constraints as a result of the pandemic. Saudi Arabian teachers used information and communication technology (ICT) in different ways than teachers in other (Organization for Economic Co-operation and Development) OECD countries: they were more likely to use ICT to supplement their training and professional development, as well as to teach (OECD, 2020d). Teachers and principals believed that the school largely facilitated the use of digital technologies in the classroom, but that inadequate internet bandwidth restricts resource utilization (OECD, 2020b). Most educators understand the significance of ICT as a teaching method and want to use it more frequently.

Educators in the GCC region were not to be more receptive to reform than those in other OECD countries, according to data from TALIS 2018 (OECD, 2019d). In the Kingdom, at least to some extent, teachers and schools collaborate. By introducing more specialized training facilities in virtual classrooms and workshops, it was possible to enhance teamwork and digital skills. Teachers were more prepared for the lockdown, but students were not. According to foreign comparisons, Saudi Arabian students are less likely to have computers and a quiet study environment. The situation of young people from the poorest socioeconomic strata, of whom only half can afford their computers for schooling, is a particular concern. While Saudi Arabian students tend to be motivated to learn, the PISA 2018 results show that they are confident in their ability to handle uncertainties (OECD, 2019a). Most students receive support from their guardians and parents who have fostered a close relationship with them.

In Saudi Arabia, schools were closed following the outbreak of the Covid-19 pandemic. When compared to other OECD nations, this time gap is greater than normal (OECD, 2020a). Television, interactive programs, and educational kits have also been used to meet the needs of students in the past. Saudi Arabia's response to 
the crisis relied heavily on national government participation, especially among local school administrators and teachers (OECD, 2019c). Officials believe that students in Saudi Arabia received adequate education when schools were closed. During the closure, Saudi teachers were aided well by principals, colleagues, teachers, and training programs, in comparison to other countries.

Schools' ability to innovate, adapt, and assist teachers in helping one another differs from one school to the other and from one country to another. At the same time, since they build successful responses to challenges, these school capacities can be strengths during uncertain times as well as useful in dealing with problems like the Covid-19 pandemic crisis (OECD, 2019b). When school budgets are slashed, schools have had to rely on out-of-the-box thinking and strategies to keep the learning going. Based on the report of the OECD's transition to remote teaching it was noted that $85 \%$ of Saudi educators "agreed" or "strongly agreed" that most educators welcome the educational reforms, similar to the TALIS survey (OECD, 2020c).

Teachers, who are scattered across the world, can only adapt to the new reality of digital learning through peer and institutional support. TALIS 2018 describes the collegial and collaborative cultures of education that existed before the Covid -19 pandemic, as well as the school leaders' role in helping to improve them. Saudi Arabia now has more than $36 \%$ of countries registered in collaborative technical learning, a figure that is above the OECD average $(21 \%)$. Interactive teachers used cognitive stimulation and other learning strategies during the Covid 19 pandemic (OECD, 2019d).

The percentage of principals in Saudi Arabia, who regularly or very often assisted in the introduction of new instructional techniques in the year before the study was much higher than the OECD average, which was higher than the OECD average (59 \%). School leaders and teachers, for example, would have access to a variety of virtual materials that aid in the communication of content and distance learning. Teachers with prior experience with online training, for example, could be able to communicate and disseminate information via online platforms (OECD, 2019c). In 2019, 22\% of teachers and participants in Saudi Arabia completed online courses, which is significantly below the OECD average (36\%).

Out-of-school learning groups may also benefit from mutual assistance. In the 2019 survey, $45 \%$ of teachers in OECD member countries were part of a teacher network that was involved in activities that promoted their career development; $43 \%$ on average in Saudi Arabia were part of a teacher network that was involved in activities that promoted their career growth, which is close to the OECD nations (40\%). Therefore, $48 \%$ of Saudi principals said they "mostly or extremely frequently worked with colleagues on challenging duties," which is above the OECD average (37 \%) (OECD, 2020d).

Out-of-classroom lessons can be somewhat compensated for, thanks to digital media and other activities, but consumer access to needed digital devices is not evenly dispersed in society. The Covid-19 crisis significantly disadvantaged students from low socioeconomic backgrounds who did not have access to these devices (Bensaid \& Brahimi, 2021). Students must have computers to participate in some form of e-learning activities (Abdulrahim \& Mabrouk, 2020). Before the Covid-19 crisis, according to previous PISA results, this criterion was not always met by all students. According to this study on computer use in Saudi Arabia, only $74 \%$ of students claimed to have an electronic device that they could use for both school and personal purposes, which is below the OECD average (89\%). The number of people from the lowest socioeconomic groups who said they had computers they could use for school was $43 \%$, again slightly below the OECD average $(78 \%)$. As a result, home computers could have been inoperable following the crisis (Thompson, 2020).

\section{The impact of Covid-19 pandemic on education in Kenya}

Even as novel coronavirus spreads, people are instituting strict cleaning protocols, social distancing interventions, and, from which when feasible, distance working and studying. In March, the majority of Western schools' doors were shut, forcing learners to complete their education online (Kathula, 2020). A year after the crisis, many schools are using new safety measures. Online education and homeschooling are both options for some students. No school policy can hope to escape all disruptions, but places were prepared to deal with "new normal" conditions, as well as possible, with required facemasks, and staggered start times. 
Education was suspended in Kenya after the first cases of Covid 19 were discovered. The task force in charge of reopening Kenyan schools decided and made a recommendation that schools may not reopen until January 2021, and only then if the region's Covid-19 curve has flattened (Battle, 2020). Kenya could not deal with the magnitude and kind of pandemic currently affecting the planet.

Meanwhile, the Kenyan government launched online educational sessions via the internet, television, and radio, however, most learners were unable to participate due to a lack of electronic devices or reliable internet access in their household (Cordeiro, 2020). Even among learners who had access to them, the lessons were delivered in a lecture format, with no teacher present to help students understand concepts (Org, 2020). Kenyan students must take national exams to advance to the next grade level, so the cancellation of school forced all students to repeat the school year and graduate a year later. Because the Kenyan school year begins in January, most students only attended classes for two months.

Working and learning from a distance have numerous advantages. The amount of time spent commuting is reduced, environmental benefits are realized, and a better work-life balance is achieved. However, there are some disadvantages (Nyamboga \& Ali, 2020). Workers can benefit greatly from online and remote working, but the growth in the latter tends to increase social disparities. Schools provide an important platform for not only academic learning but also education programs. Dietary advice, vision care, dental care, sexual and reproductive health were also included in a class or after-school programs, but online education does not provide these ancillary benefits to students, so teenage births in Kenya increased sharply in the first year of the Covid-19 pandemic due to a lack of education and supervision (Gathungu, Ojiambo, Kimathi, \& Mwalili, 2020a).

Due to the closure of all Kenyan schools, colleges and universities on March 15, the response was immediate and widespread, nearly 17 million students were affected. The closing of institutions includes huge socioeconomic issues like disrupted schooling, an increase in teenage pregnancy, housing, and food expenses, and sexual harassment (Mabeya, 2020). The outcomes for underprivileged children and their families were more extreme. Due to the government's adoption of a remote and interactive learning model, which excludes most learners because of their lack of internet connectivity and affordability, most parents were at a disadvantage when it comes to materials and Internet service when they don't have the extra money to spend on education. The decision following the Covid-19 pandemic to close schools widened the gulf between the wealthy and the poor and hindered the poor's ability to keep on learning. Consequently, there was little or no acquisition of knowledge in urban informal settlements and rural settlements where most Kenyan children reside (Areba, 2020). These groups of low-income families and underprivileged students don't have smartphones or devices hence it made it more difficult for parents to give their children proper education or help them access any type of learning online. Internet connection is costly in areas where power and technology are easy to obtain.

Extended disruptive online learning, on the other hand, impairs educational progress. Additionally, disengagement of students who may be challenged with learning disabilities who can't deal with distance learning strategies or instruction comes at a much higher price (Al-Samarrai, Gangwar, \& Gala, 2020). Children from disadvantaged backgrounds, for example, are vulnerable to dropout, for their parents might not be highly literate to be able to assist their children with their learning while struggling to afford the primary needs of their families in a period when most menial jobs were disrupted due to closures of business and restrictions of travel or work. Due to the absence of adequate planning, as well as the limited ability to reinforce their children's learning, families became focused on their children's safety, leaving no one to lead them through their schooling.

The attempt of the government to implement remote learning also had numerous hurdles because of a lack of defined infrastructure. With all of the schoolchildren out on vacation, the government had little time to get ready for the abrupt change (Beytout et al., 2021). The majority of teachers and education stakeholders had poor digital information dissemination skills and a lack of accurate information about needs for virtual instruction. As a result, there was nearly no online learning for public school children in the first nine months of the Covid-19 crisis. 


\section{The impact of Covid-19 pandemic on the time for learning in Kenya}

The Kenyan government closed all of its schools and universities on March 15, 2020, until further notice, with the intent to combat the outbreak of the Covid-19 virus. Schools were encouraged to provide online learning using the internet and technology (Onchonga, Omwoyo, \& Nyamamba, 2020). Teachers were told to make sure that their assignments could be completed at home. However, some areas of the country were denied access to broadband Internet, greatly restricting the amount of online learning available to students. Kenya, while being one of the world's leading ICT innovation centers, it was not immune to the digital divide. In many countries, digital inequity prevents those living in disadvantaged areas from accessing elearning (Kisaakye, Ndagurwa, \& Mushomi, 2021). For many households, using the Internet would cost more than a day's income. Many poor people, especially in rural areas, we're unable to use or afford laptop computers. Nearly two-thirds of Kenyan students live in rural areas, where primary and secondary schools are underfunded, and there are fewer books and virtual education services. Other factors can make it difficult for parents to comprehend how to use computers and the Internet for educational purposes other than submitting a formal assignment. Despite Kenya's literacy rate of $78.7 \%$, parents are unable to assist their children at home(Isangula et al., 2021).

While many Kenyan families have mobile phones, the majority of them do not have Internet-enabled phones. In the spring, the Pew Research Center analyzed the digital divide in 34 countries, finding that $64 \%$ of Kenyans own a mobile phone, but only $40 \%$ own a smartphone (Kiganda \& Omondi, 2020). Furthermore, electricity and Internet access are often disrupted, limiting consistent use of learning facilities. Since non-essential services were shut down and personal travel was severely limited during the Covid-19 crisis, in some periods, travel essentially came to a halt. Government-imposed quarantines and curfews in response to the Covid-19 pandemic often resulted in a learning loss. It's unknown how much learning would be disrupted during prolonged temporary closure if learners lost time during daily extended school term (Mbogo, 2020).

This risk of learning loss is heightened for rural children whose parents were illiterate and have minimal educational resources. These parents were dissatisfied not only because they were forced to homeschool their children without adequate preparation, but also because they were unable to reinforce their children's learning. Sporadic virtual education was insufficient for learners who were still lagging in content, also learning through radio is inefficient in comparison to classroom education because it is designed to supplement the knowledge that children already have.

Students who depend on meal programs provided by the school as their primary source of nutrition suffer as a result of school closures. Families' ability to feed their children was hampered even further as a result of everything going on at home. Food takes priority over schooling in such circumstances (Njura, Kubai, Taaliu, \& Shem Khakame, 2020). In Kenya, school closures have often come at a time when peasant farmers are planting, hence children from these families are more likely to be used for domestic labor. This is especially true for girls and boys who have farm work, household chores, and family obligations (Ojiambo, Kimathi, Mwalili, Gathungu, \& Mbogo, 2020). In essence, in both urban and rural areas, extended school closures had a negative effect on children through increases in child labor, drug and alcohol misuse, teen pregnancy, and underage marriages.

\section{The impact of Covid-19 pandemic on the quality of learning in Kenya}

Lack of quality education leads to several societal problems such as poverty, ill health, and social unrest, hence high-quality education alleviates societal inequities. Individuals are motivated by education to know their true worth and to have the courage to contribute to society (Bellerose, Diaw, Pinchoff, Kangwana, \& Austrian, 2020). There is an ecosystem that encourages innovation and creativity when people have a comprehensive understanding of a range of technologies and a robust educational background.

Owing to a lack of electricity in rural areas, a lack of needed materials, and a large number of students being moved to the countryside, only a small number of learners were able to get connected to the Internet for purposes of learning. Candidates in secondary and primary schools who were to sit for exams at the end of 2020 were arguably the most affected group since they could not proceed to another level of education (Janssens et al., 2021). While other candidates from other countries that sustained learning and accessed 
summative assessments proceeded to universities or secondary schools, Kenyan candidate students were left behind.

\section{The impact of Covid-19 pandemic on the content learned in Kenyan schools}

Girls, especially those from low-income families, are disproportionately vulnerable to social exclusion from educational opportunities (Cordeiro, 2020). Girls, who continue to face major educational barriers are also vulnerable to sexual exploitation and degradation, child marriage, and child trafficking due to pre-existing gender differences (Cordeiro, 2020). Girls have traditionally found a "safe harbor" in schools, which means that if they do not attend, they are more vulnerable to exploitation and abuse. As a result of the extenuating circumstances caused by Covid-19, recent local statistics show an increase in adolescent pregnancy, child labor, and sexual exploitation committed in exchange for food or money (UNDP, 2020).

Children in Kenya face a slew of additional challenges as a result of the country's widespread poverty and injustice. Education systems are still underfunded, as demonstrated by the vast number of public and private institutions that defaulted in the payment of their employees and others compelled to turn school buildings into alternative small businesses to make ends meet (eLearning Africa, 2020). Concurrently, learners from disadvantaged backgrounds, for instance, those with disabilities, those in low-income families, and those residing near armed conflict and insecurity are more likely to be marginalized (Human Rights Watch, 2020).

Children with disabilities were still underserved before the pandemic, and students in war-torn areas were often excluded from school because of the increase in violence (Human Rights Watch, 2020). These schools serve as vital sources of free school meals as well as offering education to disadvantaged children. Consequently, as the rate of unemployment of their parents rises, children had to work as a main source of revenue, without any of the support networks of school that protects them (Kiganda \& Omondi, 2020).

\section{The role of government policies on educational social inequalities}

In terms of achieving inclusive and equitable quality education; Kenya still strives to improve but the challenges increased with the outbreak of Covid-19. Increased budgetary allocation in Kenya was expected to address this problem and reaffirm that despite times of emergency, the right to education must be protected (Human Rights Watch, 2020). In practice, education must adhere to the values of availability, accessibility acceptability and adaptability to sustain equity. To achieve the standard of availability, mechanisms must be in place to allow for secure in-person and remote learning. To achieve accessibility by ensuring that every child can participate in distance learning while taking into account the particular sociopolitical and cultural challenges that vulnerable girls and children face. In this regard, mapping and tracking educational accessibility throughout the country would be helpful (Ojiambo et al., 2020). Acceptability refers to the high level of virtual and face-to-face education available in times of crisis, as well as educational resources that are culturally appropriate for the learners. While, adaptability would refer to education offered, the type of education offered during the crisis period was to be adaptable to the new societal needs as a result of the pandemic and was inclusive of all cultural settings (Bellerose et al., 2020).

In these perilous times, the concept of focusing on the indicators of equity: availability, accessibility, acceptability, and adaptability would be a powerful tool for contextualizing inequality and cultivating a culture of inclusion and cooperation inside educational systems, all while preserving children's human rights (Human Rights Watch, 2020). Educational inequalities are major public education issues today. Education exerts a significant influence on society especially the social context and education policies on life satisfaction. In the current educational system, the age of assessment, tuition, enrollment, and policy changes are interrelated and are used to measure each other (Moyi, 2020). Education affects the level of social wellbeing to a lesser degree in more egalitarian countries. For these reasons, it was posited that at the individual level, status, and income levels, policies do not exert a significant influence on educational outcomes.

The link between a school's potential to create social inequalities, as well as its ability to counter or help reduce them must be observed to alleviate social inequality in education (Maina \& Rosemary, 2019). Creation of contingency policies on education, ranging from classroom-based measures such as teaching practices, and class composition to systemic measures. The relationship between the opportunity to learn and grow is key to the current large-scale assessment and accountability system in education. For this study, an opportunity to learn refers to the amount of instructional time that focuses on high-order cognitive processes, 
and on implementing evidence-based teaching strategies (Elliott, 2015). Both opportunities to learn and grow, although frequently mentioned in education policy documents and by the teachers, are difficult to measure.

Educational opportunities were limited and stratified in most countries after the lockdown and physical school closures hence impacting the time used for learning in schools. This is an issue in lower- and uppermiddle-income countries, lower- and upper-class students alike in Sub-Saharan Africa, $45 \%$ of children had no exposure to any type of remote learning. Most people read, watched, or listened to the radio and newspapers. About $10 \%$ of children in an African country have access to the internet. The Latin American figures show that $90 \%$ of children received some remote education, but only $60 \%$ were using the internet and $40 \%$ was TV or radio (Lorente, Arrabal, \& Pulido-Montes, 2020).

Most of the country's middle-class citizens received a few hours of synchronous schooling per day. Students had to watch or listen to television to get not lower than a passing grade. For the first year of the Covid-19 pandemic, the poorest $20 \%$ of the population is expected to lose about $88 \%$ of their expected learning, but the richest quintile will "only" experienced a reduction of $64 \%$. Also note that when the pandemic began, school closures happened around the same time in the southern hemisphere, April or May (Chen, Lin, Hsueh, \& Hsieh, 2020). May and August were months during which it was difficult to find vacation ideas. The closures landed squarely on the target year to affect the year in totality. Average Latin countries have lost 160 days In-class learning dramatically declined.

In the countries with the most affluence, some students perform worse because of their background, such as where they were born or the language they speak. Educational policies and practices might reinforce (rather than reduce) the gap that currently separates these students from their peers (Thompson, 2020). These sorts of inequality are unacceptable. Some don't get to realize their true potential, aren't allowed to follow their interests, and don't develop their talents. It has social and economic repercussions. However, the case is worse when the whole country has a policy of no school attendance for an extended period of two-thirds of the academic year; this was the case of Kenya, an East African country whose ministry of education closed schools for nine months (Mabeya, 2020).

The Kenyan government announced the closing of all learning institutions nationwide on 15 March 2020 to contain coronavirus spread. More than 17 million students around the world has been plunged into limbo. The hardest affected learners are primary and secondary school students who are expected to attend their national exams by the end of 2020. In reality, Covid - 19 disrupted the landscape of the education market, restricting students' opportunity to access learning (Gathungu, Ojiambo, Kimathi, \& Mwalili, 2020b). In the aftermath of the Covid-19 pandemic, the Ministry of Education of Kenya initiated a range of initiatives designed to encourage consistency in learning. However, access to these programs is patchy and many children have not been able to profit from them. Almost 17 million learners were interrupted by the sudden closure of learning institutions in Kenya on 15 March 2020 in response to Covid-19 (Mabeya, 2020).

In Saudi Arabia however, the ministry of education with its partner ministries was able to constantly update their contingency plans over February. To make certain that the schools and learning programs would yield good outcomes; personnel from the education sector, as well as specialized committees and workgroups, were created (Al-Hanawi et al., 2020). These stakeholders ensured that learning disruption is not prolonged during the Covid-19 crisis. Subsequently, following the closures of schools and institutions of higher education; a seamless transition was made to broadcast content via satellite, YouTube, virtual classes, and online discussion platforms (MOE, 2020).

Despite the ongoing coronavirus pandemic, students in the government and private schools in Saudi Arabia have had virtual learning platforms provided by the Ministry of Education throughout the first year of the Covid-19 pandemic (Abdulrahim \& Mabrouk, 2020). They had an online scheduling program in which teacher and student interactions took place and these were done in real-time (Abolfotouh, Almutairi, Banimustafa, \& Hussein, 2020). The provision of asynchronous and synchronous learning platforms enabled students to access learning materials at all times.

\section{Methods}


This comparative study approach is aimed at sharing a common phenomenon, using the same research strategies, targeting the same research questions, and selecting the same focal variables. This research used a hybrid design that included a mixture of both quantitative and qualitative methods. The quantitative analysis used a survey research methodology, explicitly adopting an opportunity to study questionnaires with a focus on the themes of the study. This quasi cross-sectional sample design required gathering data from a wide number of people at various levels of development at one point in time.

The target demographic for the study included educators, students, and parents. The sample size for the study consisted of 44 educators, 36 parents, and 300 students selected from schools in Saudi Arabia and Kenya. This research used both the questionnaire and open-ended qualitative questions for the collection of primary data. All the data was collected online via a survey monkey questionnaire whose questions were modified to target the specific population of the study sample. Quantitative data obtained were analyzed using SPSS while the qualitative data was thematically analyzed based on the objectives of the study. Quantitative research included the use of descriptive analysis, while qualitative data were analyzed using content analysis.

\section{Results and discussion}

Social inequality in education as measured by the opportunity to learn provides three parameters that describe the baseline of equity in education. In this study, the views of participants from selected schools in Saudi Arabia and King regarding the opportunity to learn that day received during the covid-19 first year since its first infection gives a perception of what their interpretation and appreciation of the education opportunity received during this period. Since schools were physically closed in both countries due to the covid-19 pandemic, the investigation centered on alternatives provided for the continuation of education in schools in the two countries. Quantitative data provides a large difference between access to schooling provided to students in Kenyan schools and their counterparts in Saudi Arabia. The demographic characteristics of participants provide a semblance in their role as stakeholders in education hence qualifying for causal comparison in perception.

The three major components of opportunity to learn indicators used in the study guaranteed similar measures in the two population groups that are separated by country. The quality of learning received, the time of learning afforded and the continent of learning received are parameters of comparison. The demographic characteristics of participants help to explain the differences in educational inequalities in the two countries. Out of the 300 students who participated in the study with a strict cut-off of 150 students from Kenya and 150 students from Saudi Arabia with the age between 12 and 17 provided a similar range of student characteristics in terms of number and age group. Most Kenyan students did not have ready access to technology in terms of required devices and internet connectivity hence the duration of collection of data took a long time as compared to the student population in Saudi Arabia. 90\% of student respondents in Kenyan schools residence of urban environments while $100 \%$ of student respondents in Saudi Arabian schools all residents of urban environments. The population of educators and parents who participated in the survey was also divided hence providing an equal number of respondents from both countries. All respondents are students attending public schools hence provide a comparative legitimacy since bias of economic advantage due to private funding is mitigated. Although the study did not investigate the economic status of the participants, the fact that they all attended public schools in similar environments provides an opportunity for comparative analysis based on similar environments in the two countries.

In the qualitative results of narratives following open-ended questions, sentiments of stakeholders from these two countries were also variedly dissimilar. Among the most repeated sentiments on time spent learning during the first year of the Covid-19 pandemic, Kenyan parents' responses centered on the lack of infrastructure, lack of structure, and lack of supervision.

For instance

"My children's radio lessons were provided by the government during the lockdown period but the lessons were very limited in terms of time. My 16-year-old daughter only had an hour of relevant lesson per day."

"I have a radio and a television in my house but my children are too young to follow radio lessons without supervision since both their mother and myself are busy working during the day." 
"The cost of the internet in the house is too high, so the internet in my house is just on my phone hence my candidate daughters have to wait for me to come from work for them to download some past papers for their private revision."

On the other hand, Saudi Arabian parents grappled with a different set of issues including increased screentime for children, lack of physical activities during virtual lessons, and the authenticity of virtual exams. A sample of comments from parents include:

"The school schedule is too long and my young children are always in front of the computer."

"The problem of this online school is that children are just getting unfit because they don't have any activities to make them move. They only move to the fridge to take more and more snacks"

"The senior students did exams online, surely, how do you know that they were not helped by their parents and tutors? It is not fair for those students who do not get such help; better if there were no exams at all"

\section{Time spent in school in the first year of the Covid-19 pandemic}

The perception of students indicates a marginal difference in the opportunity to learn provided in both countries during the first year of the covid-19 pandemic. Kenyan students reported having spent only $20 \%$ of official School time learning whereas students from Saudi Arabia confirm the spending $90 \%$ of the official school time learning. The parents' perception of time spent learning in Kenya was only $15 \%$ while parents in Saudi Arabia rated time spent learning as $80 \%$ of official school time. Similarly, educators in Kenya reported that only $12 \%$ of official school time was used for learning while educators in Saudi Arabia rated time for learning to be $75 \%$ of official school time.

Figure 1

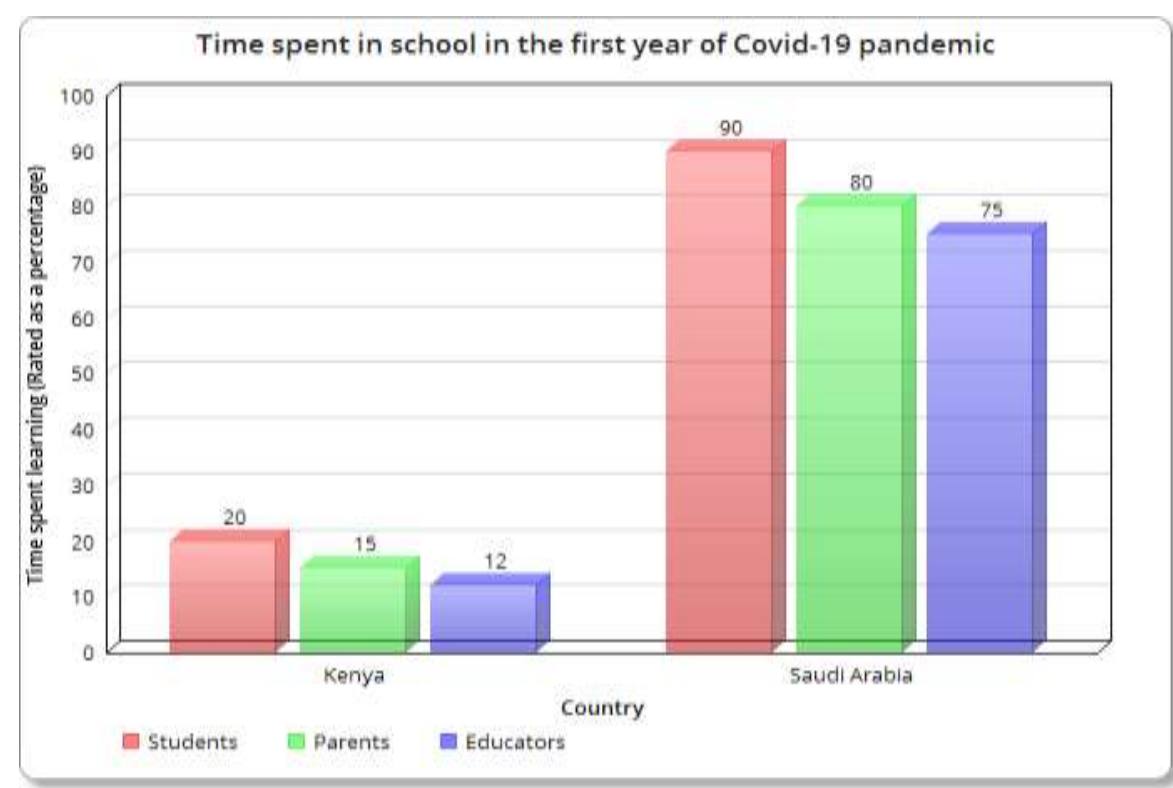

The wide disparity in access to education in these two countries during the first year of the pandemic could be accrued to several factors including government policies on schooling during the pandemic. The ministry of education in Kenya closed schools and provided a generalized alternative of education through mass media which encouraged a lack of supervision and input from educators. In Saudi Arabia, the ministry of education provided a targeted online education platform with a comprehensive supervision policy where all students and educators were required to attend. Strict monitoring of progress and attendance characterized the virtual learning environment of Saudi Arabia whereas the Kenyan system did not apply for students and educators to attend or continue the learning process. Besides, which time required for schooling in Saudi Arabia was prescribed by the ministry of education where elementary students learned from 3 p.m. while middle school and high school students started their virtual classes at 9 am. This prescriptive approach according to $94 \%$ of participants contributed to the success of continuity in learning in Saudi Arabian during the first year of the covid-19 pandemic.

The lack of structure and accountability was rated by $80 \%$ of respondents in Kenya to be one of the main 
reasons for reduced time spent for learning. Government policies and regulations in these two countries contributed to the wide disparity in the opportunity to learn in times of time spent learning during official school time in the first year of the covid-19 pandemic. The government whose policies and regulations remained structured and demanded accountability received a higher rating from the education stakeholders' perception of the time spent learning by students during School official time in the first year of the covid-19 pandemic.

\section{Quality of learning in school in the first year of Covid-19 pandemic}

The quality of learning would be described as the details embedded in the learning process which includes preparation for instruction, delivery of instruction, assessment of learning, and assessment for learning. In the first nine months of the first year of the covid-19 pandemic, the ministry of education in Kenya did not require formal learning processes to continue in public schools. As a result, there was no formal and guided instruction for students in the first nine months until schools reopened in the last three months of the first year of the covid-19 pandemic. Since only one-third of the first year of the covid-19 pandemic was used for formal and guided instruction, the perception of participants rated quality of learning as poor due to the lack of formal instruction in the first three quarters of the first year of the covid-19 pandemic. Lack of access to a structured instructional process, compromised the quality of learning hence contributing to limited access to learning. Participants in this study rated the quality of learning in Kenyan schools during the first year of the covid-19 pandemic at an average of $18.3 \%$ while their counterparts in Saudi Arabia rated the quality of learning at an average of $70 \%$.

Figure 2

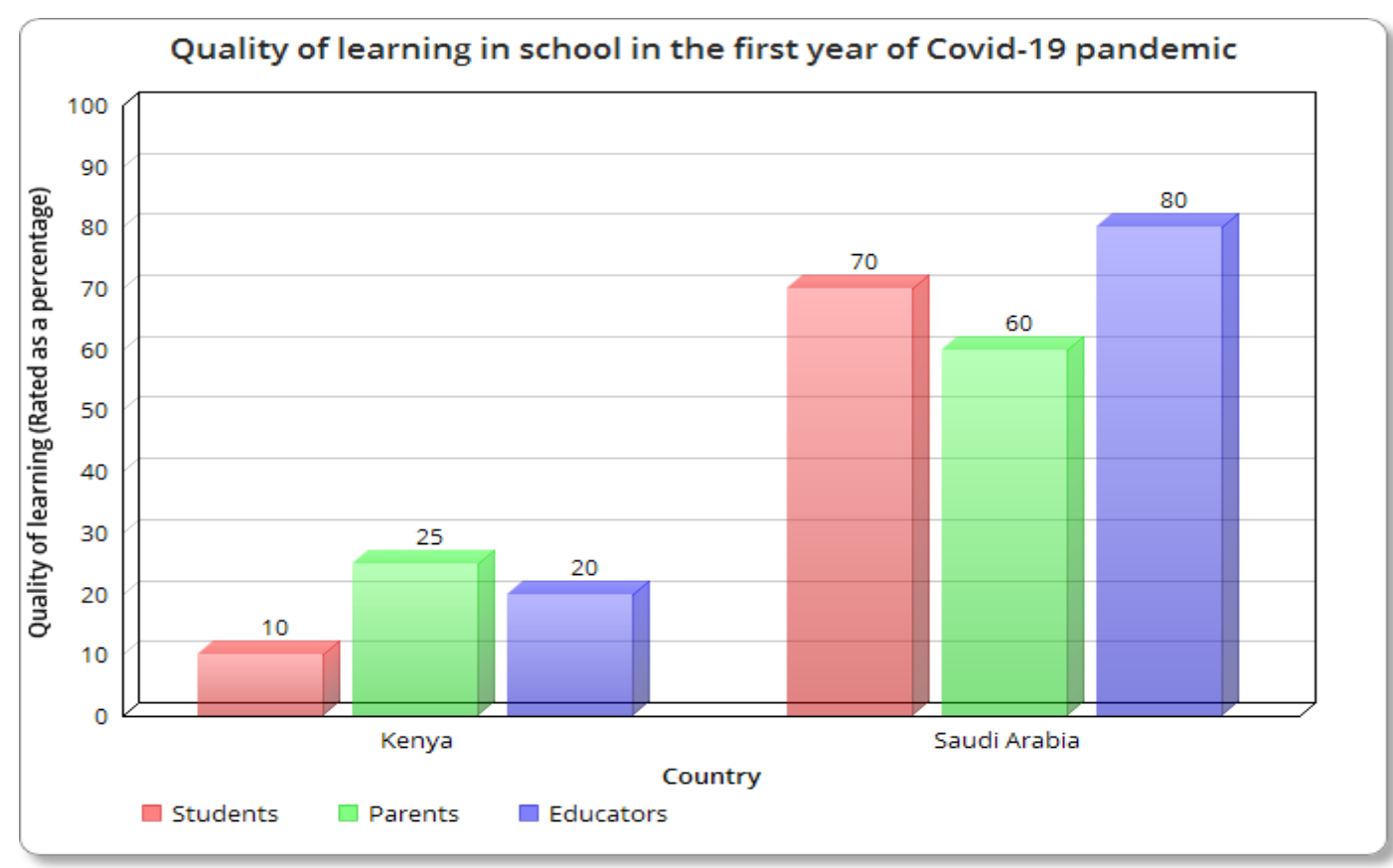

During the first year of the covid-19 pandemic, Saudi Arabia transitioned to virtual learning with full-time supervision of the program needed synchronous and asynchronous learning sessions for all students. The government regulation and policy required all students to attend the virtual classes and compelled all teachers to supervise and monitor attendance. Monitoring and accountability were a requirement to the leadership while the minister of education kept a central database that tracked attendance and continuously sensitized parents on the importance of students' attendance in their virtual classes. Teachers were required to prepare for instruction, deliver the instruction, and provide a continuous assessment to prepare students for summative assessments at the end of semesters.

By the end of the academic year, the promotion of students was done and continuity of learning was interrupted through the progression of students to the next grades. Although the Kenyan schools open for physical attendance of school by students and teachers in the last quarter of the first year of the covid-19 pandemic, the ministry of education had to revise the academic calendars since there was no progression and promotion achieve during the nine months of the closure of formal structured learning. Saudi Arabia, on the other hand, remained to implement virtual education but achieved higher ratings in quality of learning by 
education stakeholders. In essence, the quality of learning based on the results of this study is a result of the consistent application of structured learning processes with constant monitoring and accountability to all stakeholders involved. Management of educational programs at a macro level provides direction that has a direct impact on the quality of education received.

\section{The content learned school in the first year of Covid-19 pandemic}

The content of learning in public education systems in both Saudi Arabia and Kenya is prescribed by the respective ministry of education. Therefore, the content required for instruction is tracked by the ministry of education and the schools' role is to implement what has been received. Books and resources are also provided by these governments to schools hence the knowledge of what needs to be completed within a period on the syllabus are centrally structured. Therefore, measuring the content covered by public schools can be done by evaluating the coverage of the class syllabus provided by the ministry of education. The coverage of the class syllabus is only achieved when schools are in session and instruction is active. In Kenyan schools, there was no instruction in the first nine months of the first year of the covid-19 pandemic hence the content coverage was only one-third which was achieved when schools physically opened. On the contrary, Saudi Arabia continued with content coverage during the whole year of virtual education.

\section{Figure 3}

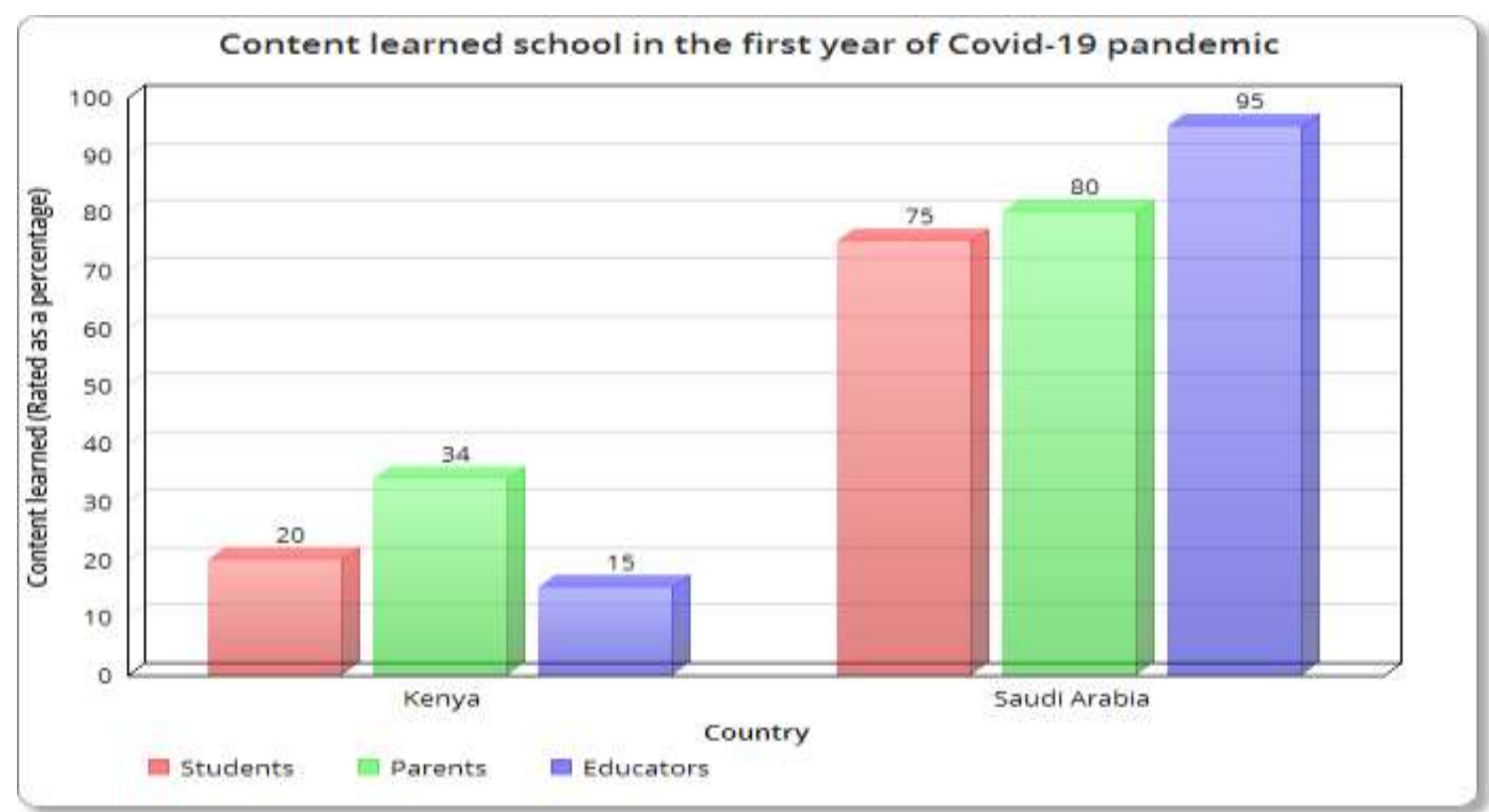

Based on the perception of participants in this study, students, parents, and educators in Kenya believe that only $20 \%, 34 \%$, and $15 \%$ of the annual content was covered respectively. Participants from Saudi Arabia who are educators believe that $90 \%$ of the required content was covered, parents believe that $80 \%$ of the content was covered and students feel that $75 \%$ of the content was covered. The discrepancies between perceptions of subgroups could be explained by the delivery of knowledge and interaction with educational materials that each subgroup has. For instance, educators have a better understanding of how much content is required as compared to parents who may not be directly involved in the educational process. Therefore, educators in Saudi Arabia report having completed 90\% of the required content while those in Kenya reported having only completed $15 \%$ of the curriculum in the first year of the covid-19 pandemic.

\section{Conclusion, Limitations, and Recommendation}

There is a wide margin of disparity of opportunities to learn afforded to students in Saudi Arabia and Kenya during the same period of time, the first year of the Covid-19 pandemic. This disparity contributes to the rising inequality in education between countries. It is notable that Saudi Arabia reported higher rates of Covid-19 infection and death cases than Kenya in the first year of Covid-19 infection but still had a better system of educational continuity. It is also key to note that Saudi Arabia maintained a whole year on virtual education only while Kenya opened physical attendance in all levels of educational institutions in the last quarter of the first year of the Covid-19 pandemic. Despite the earlier opening of physical attendance in schools, Kenya still rated lower on the provision of opportunities to learn to students. 
Comparative studies aim to construct generalized theories from specific ones, as well as to build theories of widespread application. The theory-development view is generally viewed as seeking to understand similarities and differences. Instead, an analogy can and should be made to gather causal relationships. In other words, it is aimed at proving a hypothesis on the majority, if not all, of the cases. While the developed degree of generality and applicability of the theory differs, there is an assumption that analogy may and should be used to arrive at different models to transcend the unique cases. This study assumes the limitation of this methodology hence the need and the recommendation for a further in-depth analytical investigation that nullifies the weakness of this methodology.

Based on the findings of this generalized comparative study, it may be recommended that educational policies that intend to foster equity and justice in education must include the role of opportunities to learn in their structure. The lessons from this comparative study lie in the process of policy formation and policy implementation by educational stakeholders in times of crisis. When policies are made with an emphasis on time, content, and quality of learning; continuity of education as a contingency plan is achieved.

\section{References}

1. Abdulrahim, H., \& Mabrouk, F. (2020). COVID-19 and the digital transformation of Saudi higher education. Asian Journal of Distance Education, 15(1).

2. Abolfotouh, M. A., Almutairi, A. F., Banimustafa, A. A., \& Hussein, M. A. (2020). Perception and attitude of healthcare workers in Saudi Arabia with regard to Covid-19 pandemic and potential associated predictors. BMC Infectious Diseases, 20(1). https://doi.org/10.1186/s12879-020-05443-3

3. Al-Hanawi, M. K., Angawi, K., Alshareef, N., Qattan, A. M. N., Helmy, H. Z., Abudawood, Y., ... Alsharqi, O. (2020). Knowledge, Attitude and Practice Toward COVID-19 Among the Public in the Kingdom of Saudi Arabia: A Cross-Sectional Study. Frontiers in Public Health, 8(May), 1-10. https://doi.org/10.3389/fpubh.2020.00217

4. Al-Samarrai, S., Gangwar, M., \& Gala, P. (2020). The Impact of the COVID-19 Pandemic on Education Financing. The Impact of the COVID-19 Pandemic on Education Financing, (May), 1-12. https://doi.org/10.1596/33739

5. Areba, G. N. (2020). COVID-19 Pandemic Impact on Kenyan Education Sector: Learner Challenges and Mitigations. Journal of Research Innovation and Implications in Education, 4(2), 128-139. Retrieved from https://jriie.com/covid-19-pandemic-impact-on-kenyan-education-sector-learnerchallenges-and-mitigations/

6. Battle, D. E. (2020). The Impact of COVID-19 on Health Care, Education, and Persons With Disabilities in Kenya. Perspectives of the ASHA Special Interest Groups, 5(6), 1793-1796. https://doi.org/10.1044/2020_persp-20-00097

7. Bellerose, M., Diaw, M., Pinchoff, J., Kangwana, B., \& Austrian, K. (2020). Pre-pandemic Influences on Kenyan girls' transitions to adulthood during COVID-19. Girlhood Studies, 13(3). https://doi.org/10.3167/GHS.2020.130310

8. Bensaid, B., \& Brahimi, T. (2021). Coping with COVID-19: Higher Education in the GCC Countries. https://doi.org/10.1007/978-3-030-62066-0_12

9. Beytout, Q., Pepiot, J., Maruani, A., Devulder, D., Aubert, R., Beylot-Barry, M., ... Mahé, E. (2021). Impact of the COVID-19 pandemic on children with psoriasis. Annales de Dermatologie et de Venereologie. https://doi.org/10.1016/j.annder.2021.01.005

10. Chen, R. J. C., Lin, H. C., Hsueh, Y. L., \& Hsieh, C. C. (2020). Which is more influential on teaching practice, classroom management efficacy or instruction efficacy? Evidence from TALIS 2018. Asia Pacific Education Review, 21(4). https://doi.org/10.1007/s12564-020-09656-8

11. Cordeiro, V. C. (2020). Is 2020 a Lost Academic Year? The Impact of COVID-19 on Education in Eastern Africa: A Case Study of Kenya. 53(1), 1-8.

12. eLearning Africa. (2020). The effect of Covid-19 on education in Africa and its implications for the use of technology. EdTech. https://doi.org/10.5281/zenodo.4018774

13. Elliott, S. N. (2015). Measuring Opportunity to Learn and Achievement Growth: Key Research Issues With Implications for the Effective Education of All Students. Remedial and Special Education, 36(1), 58-64. https://doi.org/10.1177/0741932514551282

14. Floden, R. E. (2002). The measurement of opportunity to learn. Methodological Advances in CrossNational Surveys of Educational Achievement, (2002), 243-278. 
15. Gathungu, D. K., Ojiambo, V. N., Kimathi, M. E. M., \& Mwalili, S. M. (2020a). Modeling the effects of non-pharmaceutical interventions on COVID-19 spread in Kenya. MedRxiv. https://doi.org/10.1101/2020.05.14.20102087

16. Gathungu, D. K., Ojiambo, V. N., Kimathi, M. E. M., \& Mwalili, S. M. (2020b). Modeling the Effects of Nonpharmaceutical Interventions on COVID-19 Spread in Kenya. Interdisciplinary Perspectives on Infectious Diseases, 2020. https://doi.org/10.1155/2020/6231461

17. Human Rights Watch. (2020). Impact of Covid-19 on Children's Education in Africa Submission to The African Committee of Experts on the Rights and Welfare of the Child 35th Ordinary Session. (September). Retrieved from https://www.hrw.org/sites/default/files/media_2020/08/Discussion Paper - Covid for ACERWC.pdf

18. Isangula, K., Edwards, G., Mwansisya, T., Mbekenga, C., Pallangyo, E., Sarki, A., \& NdiranguMugo, E. (2021). Open and distance learning programs for nursing and midwifery education in East Africa: Protocol for a scoping review. JMIR Research Protocols, 10(1). https://doi.org/10.2196/17765

19. Janssens, W., Pradhan, M., de Groot, R., Sidze, E., Donfouet, H. P. P., \& Abajobir, A. (2021). The short-term economic effects of COVID-19 on low-income households in rural Kenya: An analysis using weekly financial household data. World Development, 138. https://doi.org/10.1016/j.worlddev.2020.105280

20. Kathula, D. N. (2020). Effect of Covid-19 Pandemic on the Education System in Kenya Dr . Domeniter Naomi Kathula Effect of Covid-19 Pandemic on the Education System in Kenya. Stratford Peer Reviewed Journals and Book Publishing.

21. Kiganda, E. O., \& Omondi, M. A. (2020). Corona Virus Disease (COVID-19) and Other External Factors as Determinants of Accommodation and Restaurant Services in Kenya. Archives of Current Research International. https://doi.org/10.9734/acri/2020/v20i730210

22. Kisaakye, P., Ndagurwa, P., \& Mushomi, J. (2021). An assessment of the availability of handwashing facilities in households from four East African countries. Journal of Water, Sanitation and Hygiene for Development, 11(1). https://doi.org/10.2166/washdev.2020.129

23. Lorente, L. M. L., Arrabal, A. A., \& Pulido-Montes, C. (2020). The right to education and ICT during covid-19: An international perspective. Sustainability (Switzerland), 12(21), 1-17. https://doi.org/10.3390/su12219091

24. Mabeya, M. T. (2020). Distance Learning During COVID-19 Crisis: Primary and Secondary School Parents Experiences in Kenya. East African Journal of Education Studies, 2(1). https://doi.org/10.37284/eajes.2.1.249

25. Maina, G., \& Rosemary, W. (2019). Digital literacy enhancement status in Kenya's competencybased curriculum. IFIP Advances in Information and Communication Technology, 564. https://doi.org/10.1007/978-3-030-28764-1_23

26. Mbogo, R. W. (2020). Leadership Roles in Managing Education in Crises: The Case of Kenya During Covid-19 Pandemic. European Journal of Education Studies, 7(9). https://doi.org/10.46827/ejes.v7i9.3250

27. MOE. (2020). The Saudi MOE leading efforts to combat the coronavirus pandemic (COVID-19). Ministry of Education, 1-80.

28. Moyi, P. (2020). Out of Classroom Learning: A Brief Look at Kenya's COVID-19 Education Response Plan. International Studies in Educational Administration, 48(3).

29. Njura, H. J., Kubai, K. I., Taaliu, S. T., \& Shem Khakame, K. (2020). The Relationship between Agricultural Teaching Approaches and Food Security in Kenya. Education Research International, 2020. https://doi.org/10.1155/2020/8847864

30. Nyamboga, T. O., \& Ali, H. A. (2020). Adoption of Digital Literacy Strategy on Academic Progress of Private University Education in Kenya: A Survey of Umma University, Garissa Campus. Asian Journal of Economics, Business, and Accounting. https://doi.org/10.9734/ajeba/2020/v19i230300

31. OECD. (2019a). PISA 2018 Results. OECD Publishing, III.

32. OECD. (2019b). PISA 2018 Results What Student Student Know and Can Do. In PISA 2018 Results (Volume I): Vol. I.

33. OECD. (2019c). Programme for international student assessment (PISA)- Results from PISA 2018 Ireland. OECD Report 2019 - Country Note: Malaysia. 
34. OECD. (2019d). TALIS 2018 Results - Teachers and School Leaders as Lifelong Learner (Volume I). In The Learning Professional (Vol. 40).

35. OECD. (2020a). A Teachers' Guide to TALIS 2018, volume 2. British Journal of Special Education, $1(1)$.

36. OECD. (2020b). Education and Covid-19: Focusing on the Long-Term Impact of School Closures. Oecd, (June).

37. OECD. (2020c). TALIS 2018 Results (Volume II). In The Learning Professional (Vol. 40).

38. OECD. (2020d). The impact of COVID-19 on student equity and inclusion: supporting vulnerable students during school closures and school re-openings. OECD Publishing.

39. Ojiambo, V. N., Kimathi, M., Mwalili, S., Gathungu, D., \& Mbogo, R. W. (2020). A humanpathogen SEIR-P model for COVID-19 outbreak under different intervention scenarios in Kenya. MedRxiv. https://doi.org/10.1101/2020.05.15.20102954

40. Onchonga, D., Omwoyo, J., \& Nyamamba, D. (2020). Assessing the prevalence of self-medication among healthcare workers before and during the 2019 SARS-CoV-2 (COVID-19) pandemic in Kenya. Saudi Pharmaceutical Journal, 28(10). https://doi.org/10.1016/j.jsps.2020.08.003

41. Org, H. K. (2020). The Impact of Covid-19 on Education in Kenya Education and Childhood Development in Kenya.

42. Thompson, M. C. (2020). The Impact of the Coronavirus Pandemic on the Socioeconomic Future of Young Saudis. Asian Journal of Middle Eastern and Islamic Studies, 14(3). https://doi.org/10.1080/25765949.2020.1808375

43. UNDP. (2020). Articulating the Pathways of the Socio-Economic Impact of the Coronavirus Pandemic on the Kenyan Economy. Policy Brief, 4/2020(April), 33.

44. Worldometer. (2021). Covid-19 Coronavirus Pandemic. 